\title{
Pecuária e desmatamento: \\ uma análise das principais causas diretas \\ do desmatamento na Amazônia
}

Sérgio Rivero

Doutor em Ciências Sócio Ambientais do Centro de Pesquisas Econômicas da Amazônia (CEPEC-UFPA)

Oriana Almeida Ph.D. em Ciências Ambientais do Núcleo de Altos Estudos Amazônicos (NAEA-UFPA)

Saulo Ávila

Analista de sistemas do Centro de Pesquisas Econômicas da Amazônia (CEPEC-UFPA) e bolsista CNPq

Wesley Oliveira

Economista do Centro de Pesquisas Econômicas da Amazônia (CEPEC-UFPA) e bolsista CNPq

\section{Palauras-chave}

desmatamento, Amazônia, pecuária, dados em painel.

Classificação JEL Q24, Q28.

Key words

deforestation, Amazon, cattle ranching, panel data analysis.

JEL Classification Q24, Q28.

\section{Resumo}

Na Amazônia Brasileira a principal atividade responsável pelo desmatamento é a pecuária. Esse trabalho analisa a evolução das causas imediatas do desmatamento da Amazônia, utilizando-se de regressões lineares com dados em painel. O modelo avalia a contribuição dos principais usos do solo na região ao desmatamento, de 2000 a 2006. Dados do PRODES de desmatamento, o número de cabeças bovinas de 782 municípios da Amazônia e área plantada de culturas perenes e temporárias foram utilizados para essa análise. O resultado mostrou que o desmatamento é fortemente correlacionado com a pecuária. A soja também aparece positivamente correlacionada com o desmatamento. Esta tendência é reforçada pelo crescimento nacional e internacional da demanda de carne. Políticas públicas eficazes para a redução do desmatamento devem, portanto, agir nas causas subjacentes da expansão da pecuária reduzindo a força dos processos que produzem a sua expansão na fronteira do desmatamento.

\section{Abstract}

Cattle Ranching is the main causes of deforestation in the Brazilian Amazon region.

This paper analyses the proximate causes of deforestation using linear regressions with panel data. The model evaluates the contribution of the main land uses for deforestation from 2000 to 2006. Deforestation data from INPE-PRODES, number of heads of cattle, and area of temporary and permanent crops from IBGE are the data used in the analysis

(782 municipalities). The result of the regressions shows that deforestation is strongly associated with cattle ranching. Soybean plantations are also strongly related with deforestation in the model. This trend is reinforced by the growth in demand for meat in the domestic and international markets. To be effective in reducing deforestation rates, public policies must therefore act on the underlying causes of deforestation, reducing the forces that lead to its expansion on the area where deforestation is occurring. 


\section{1_Introdução}

O desmatamento ${ }^{1}$ na Amazônia brasileira tem como principais causas diretas a pecuária, a agricultura de larga escala e a agricultura de corte e queima. Dessas causas, a expansão da pecuária bovina é a mais importante. A remoção temporária ou parcial da floresta para a sua conversão em áreas de pastos e agrícolas associadas com a extração seletiva de madeira emite uma entre 0,6 e 0,9 (+/- 0,5) PgC.ano ${ }^{-1}$. Isso representa, segundo algumas recentes estimativas, de $15 \%$ a $35 \%$ da emissão global média de combustíveis fósseis na década de 1990 (Defries et al., 2002). De acordo com a FAO, a maior taxa de desmatamento ocorreu no Brasil, seguido da Índia, da Indonésia, do Sudão e da Zâmbia (Houghton, 2005). No Brasil, a maioria dos estudos já tem demonstrado que o desmatamento tem sido causado pela conversão de floresta, principalmente para pecuária, agricultura de corte e queima ou associada à exploração madeireira (Arima et al., 2005; Veríssimo et al., 1996; Ferreira et al., 2005).

O principal objetivo deste trabalho é analisar, com base nos dados dos municípios da Amazônia Legal brasileira, como evoluíram, nos anos recentes, as principais causas diretas do desmatamento. Isso foi feito utilizando-se uma série de regressões lineares múltiplas com dados em painel coletados valendo-se de fontes secundárias (IBGE, Ipeadata, INPE) para 782 municípios selecionados dos Estados da Amazônia Legal. Esse modelo econométrico simples permite avaliar a contribuição dos acordos principais dos usos do solo para o desmatamento de 2000 a 2006 e, consequentemente, estimar o impacto desses usos nas dinâmicas atuais e futuras da expansão do desmatamento. $\mathrm{O}$ trabalho também analisa o potencial de expansão da atividade pecuária associado às novas dinâmicas de demanda nacional e global e da organização da indústria de carne na Amazônia.

\section{As causas do desmatamento na Amazônia brasileira e seus modelos}

Kaimowitz e Angelsen (1998), em sua análise de 150 modelos do desmatamento de florestas tropicais, definem desmatamento como a "remoção completa e no longo prazo da cobertura de árvores". Essa é a definição de desmatamento que se usará neste artigo. O estudo das causas do desmatamento feito por Geist e Lambin (2001 e 2002) aponta que o que eles chamam de causas próximas do desmatamento está associado com os usos do solo e afeta diretamente o ambiente e a cobertura vegetal. Esses autores associam
Entendido aqui como o corte raso da floresta. 
as causas próximas (chamadas aqui de causas diretas) do desmatamento em três categorias, a saber: expansão das pastagens e áreas agrícolas, extração de madeira e expansão da infraestrutura. Tais mudanças do uso do solo são dirigidas por processos econômicos que as sustentam. Essas causas mais profundas do processo de desmatamento são chamadas pelos autores de causas subjacentes e estão associadas com o crescimento dos mercados para os produtos que produzem a mudança de uso do solo, com a urbanização e com o crescimento populacional, com fatores estruturais, culturais e, finalmente, com políticas governamentais.

As causas subjacentes dos processos de desmatamento são pouco suscetíveis a uma análise quantitativa, visto que, em geral, modelos econométricos que mapeiam os usos do solo ou seus condicionantes mais imediatos (como crescimento populacional ou urbanização) tendem a ter pouca eficácia de análise, quando do mapeamento de processos mais complexos como o comportamento dos agentes e de suas decisões individuais; os impactos de expectativas e de políticas públicas, bem como aspectos mais difusos como aprendizado e cultura nas dinâmicas de expansão das atividades econômicas que são causas diretas do desmatamento.
Modelos que mapeiem consistentemente os atores, os processos decisórios e o ambiente institucional que produz as dinâmicas de expansão do desmatamento na Amazônia implicam uma ampliação do escopo de análise que comumente tem sido utilizado na maioria dos estudos sobre essa temática. Estudos econométricos, em geral, tentam associar os resultados dos processos de desmatamento com causas objetivas diretas mensuráveis (uma consequência óbvia da metodologia, claro), mas tendem a avançar pouco sobre as determinações das decisões dos atores (Kaimowitz e Angelsen, 1998, p. 5-6). Modelos que observem o comportamento dos atores num nível individual e também os dados numa abordagem regionalizada podem ser mais úteis para esclarecer consistentemente as dinâmicas associadas às causas subjacentes dos processos de desmatamento.

O reconhecimento dos problemas associados aos modelos comumente utilizados para a análise das causas do desmatamento não impede, porém, de lhes avaliar a validade. Um aspecto fundamental associado a esses modelos, quando se fala em causas diretas do desmatamento, é o de mapear estatisticamente o peso de cada tipo de uso do solo no processo. Nesse sentido, uma análise de vários estudos econométricos sobre as causas do desmatamento parece 
ser um bom ponto de partida para mapear os achados e os espaços ainda não analisados do problema.

Por meio da modelagem do processo de desmatamento, em um trabalho pioneiro, Reis e Margulis (1991) projetaram as emissões futuras de carbono da Amazônia Legal. O modelo desenvolvido pelos autores descreve a relação entre a densidade espacial das principais atividades econômicas e a fração da área desmatada, utilizando o efetivo bovino, a área de cultura agrícola (lavoura permanente e temporária), a densidade de população, as rodovias e a extração de madeira como variáveis. A variável área agrícola apresentou o maior valor para a elasticidade do desmatamento, seguida da população e da densidade de rodovias. Os autores trabalharam com modelos cross-section, relacionando o crescimento entre 1980 e 1985 à densidade da população; área agrícola, número de bovinos e extração madeireira em 1980 foram estimadas a fim de fazer as previsões dos padrões de crescimento de cada atividade no futuro.

A análise das interações entre os processos de desmatamento, ocupação agropecuária, urbanização e industrialização constitui a base do modelo de Reis (1996). Segundo esse modelo, as causas principais da ocupação econômica da Amazônia Legal são a expansão da malha rodoviária e o crescimento populacional, sendo a atividade agropecuária a principal causa imediata do processo de desmatamento, tendo o setor madeireiro papel secundário.

Já Andersen e Reis (1997) fizeram uma comparação entre crédito e abertura de estradas. No estudo, os autores afirmam que o impacto da abertura de estradas é muito pior que o do crédito, uma vez que causa grande desmatamento e pequeno aumento da produção. Contudo, o crédito agrícola, apesar de ser mais eficiente, é também muito menos equitativo, já que as estradas permitem o acesso dos pobres às terras da União. Os investimentos em infraestrutura e serviços atraem empreendedores, que, por sua vez, atraem migrantes, tendo como consequência o aumento da população e a demanda por serviços básicos e de infraestrutura, onde exige a presença do governo.

Young (1998), analisando os mecanismos que causaram o desmatamento na Amazônia Legal, nas décadas de 1970 e 1980, verificou uma relação positiva entre a variação da área agrícola e a variação no tempo dos preços agrícolas, da construção de rodovias, do preço da terra e dos créditos. Registrou, porém, uma relação negativa com o salário rural. Para Margulis (2001), os maiores preços agrícolas estimulam a busca por terras e, em consequência, o desmatamento. 
Ferraz (2000) buscou analisar as causas da expansão agrícola e da pecuária entre 1980 e 1995 através de modelo de regressão múltipla, relacionando as variáveis dependentes (conversão de floresta em área agrícola e conversão de floresta em pecuária) com as variáveis explicativas de extensão de rodovias pavimentadas e não pavimentadas, crédito agrícola, preço de insumos, preço da produção. O autor argumenta que a expansão agrícola é determinada pelos aumentos de preço da terra, redução do salário rural, crédito rural e rodovias. Quanto à expansão da pecuária, os resultados do autor apontam para o crescimento da malha rodoviária como a causa principal. Segundo Margulis (2001), o preço da terra pode ter efeito dual, dependendo do seu uso, se para fins produtivos ou lucrativos. Portanto, menores preços da terra estimulam o desmatamento, quando usado para fins produtivos. Para o mesmo autor, o preço dos insumos pode também ter efeito dual no desmatamento, ou seja, um aumento deles causa uma diminuição da lucratividade da agricultura e, portanto, no desmatamento; por outro lado, força a substituição da produção intensiva pela extensiva, portanto mais desmatamento.

Para Margulis (2003), não seriam rodovias (ou estradas) por si mesmas que levariam ao desmatamento, mas sim a via- bilidade financeira da pecuária. Os madeireiros e depois os pecuaristas as constroem se houver viabilidade. Segundo o autor, não há dúvida de que a redução dos custos de transportes propiciada pelos investimentos nos grandes eixos rodoviários tornou lucrativa a implantação de atividade agropecuária, que, anteriormente, era considerada inviável. Essa consideração sobre a importância da pecuária como motor do processo de desmatamento feita por Margulis é consistente com os números encontrados para a expansão e a participação dessa atividade no uso do solo na Amazônia.

É preciso também compreender o desmatamento como um processo que tem causas diretas associadas ao uso do solo, mas que também tem causas subjacentes ligadas ao ambiente institucional e às expectativas de rentabilidade dos investimentos dos agentes. Esse conjunto complexo de causas acaba por resultar em dinâmicas agregadas de larga escala que têm, muitas vezes, características comuns para toda a Amazônia Legal.

\section{3_A estrutura dos processos de desmatamento na Amazônia em uma base municipal}

Usando dados do Prodes (INPE, 2008) para o desmatamento, analisou-se a distri- 
buição percentual do desmatamento por classe para 782 municípios da região. Estabeleceram-se quatro classes de desmatamento, quais sejam: os municípios com menos de $20 \%$ de área desmatada, os municípios com $20 \%$ a menos de $50 \%$ de área desmatada, os municípios com 50\% a menos de $80 \%$ de área desmatada e os municípios com mais de $80 \%$ de área desmatada. Para o cálculo do percentual de área desmatada, usou-se o tamanho da área de não floresta calculada no ano 2000 para os municípios. Com base nessa classificação, analisou-se a presença dos municípios em cada classe de desmatamento (Tabela 1).

Analisou-se a distribuição do número dos municípios por classe de desmatamento de 2000 a 2006. Nessa análise, podese comprovar uma mudança significativa na distribuição da participação dos municípios. O número de municípios com menos de $20 \%$ de área de não floresta desmatada reduziu de 446 em 2000 para 354 em 2006. Ao mesmo tempo, houve um crescimento dos municípios com $80 \%$ de área de não floresta desmatada de 103 em 2000 para 150 em 2006. Também há expressivo crescimento dos municípios com 50-80\% de área desmatada de 117 para 150 no mesmo período.

Mais do que "uma dança de cadeiras", esses números expressam uma dinâmica de expansão dos processos de desmatamento que ocorre em todos os municípios da região. Tal desmatamento parece estar associado a processos endógenos de expansão das atividades agropecuárias, além da já discutida expansão da fronteira do arco de desmatamento. Isto é, apesar de uma redução nas taxas de desmatamento nas regiões de ocupação mais densa e antiga, os processos de desmatamento tendem a ter uma dinâmica própria, associada à expansão dos cultivos e das pastagens e aos novos investimentos nas áreas já ocupadas.

Tabela 1_ Número de municípios por classe de percentual de desmatamento - 2000-2006

\begin{tabular}{c|c|c|c|c|c|c|c}
\hline$\%$ Desmatamento & $\mathbf{2 0 0 0}$ & $\mathbf{2 0 0 1}$ & $\mathbf{2 0 0 2}$ & $\mathbf{2 0 0 3}$ & $\mathbf{2 0 0 4}$ & $\mathbf{2 0 0 5}$ & $\mathbf{2 0 0 6}$ \\
\hline$<20$ & 446 & 391 & 387 & 371 & 367 & 360 & 354 \\
\hline $20-50$ & 115 & 129 & 125 & 130 & 127 & 127 & 127 \\
\hline $50-80$ & 117 & 139 & 140 & 144 & 145 & 146 & 150 \\
\hline$>80$ & 103 & 122 & 129 & 136 & 142 & 148 & 150 \\
\hline$\ldots$
\end{tabular}

Fonte: INPE (2008). 
Então, diferentemente de uma dinâmica exclusivamente expansionista associada à incorporação de novas áreas à produção agropecuária regional, dentro das áreas antigas, o desmatamento também continua acontecendo. Há que se lembrar que os municípios que têm os menores percentuais de áreas desmatadas também têm, em geral, as maiores áreas em termos absolutos, o que significa que há diferenças em termos de volume de área desmatada para cada classe de município. Isso, porém, reforça o fato de que, além da expansão para novas áreas, o desmatamento continua ocorrendo (mesmo que em proporções menores) nas áreas da chamada fronteira consolidada.

Observando-se a espacialidade do processo de desmatamento, pode-se constatar que a expansão segue também uma dinâmica que tem uma associação bastante específica (Figuras 1 e 2).

\section{Figura 1_ Desmatamento classe de área e municípios (2000)}

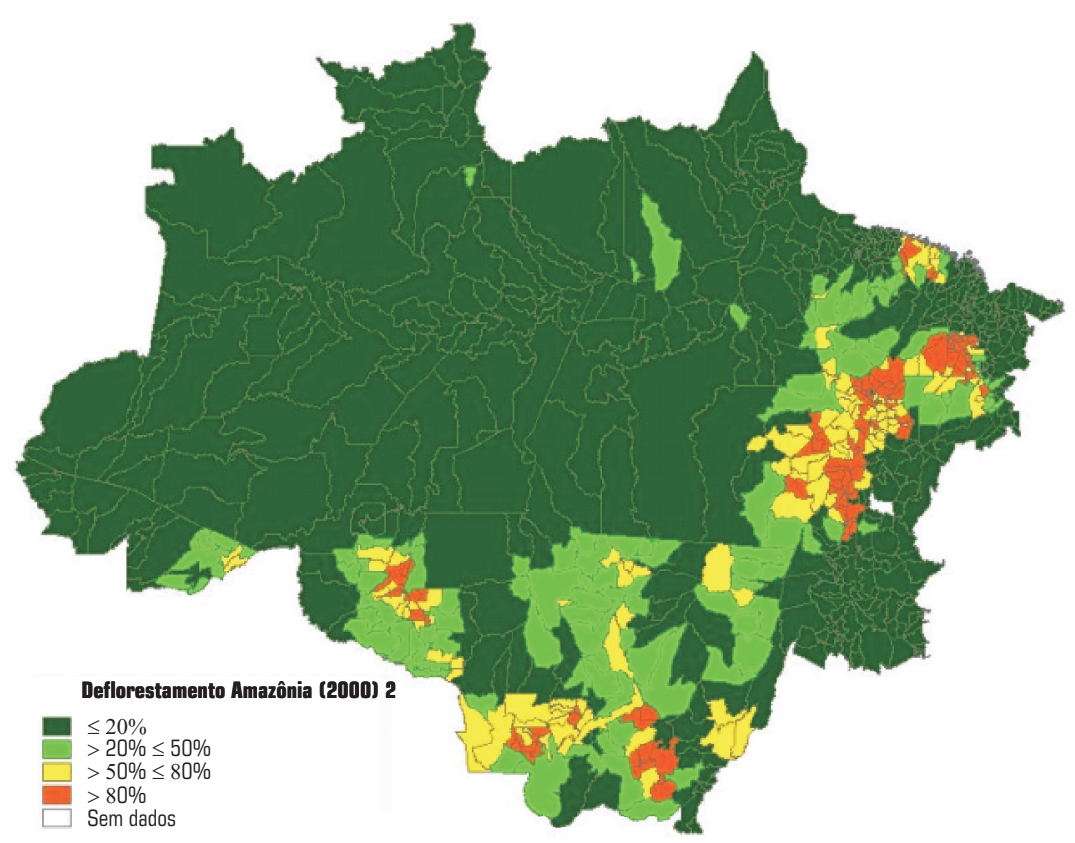

Fonte: INPE (2008) - Elaboração dos Autores. 
Figura 2_Desmatamento classe de área e municípios (2006)

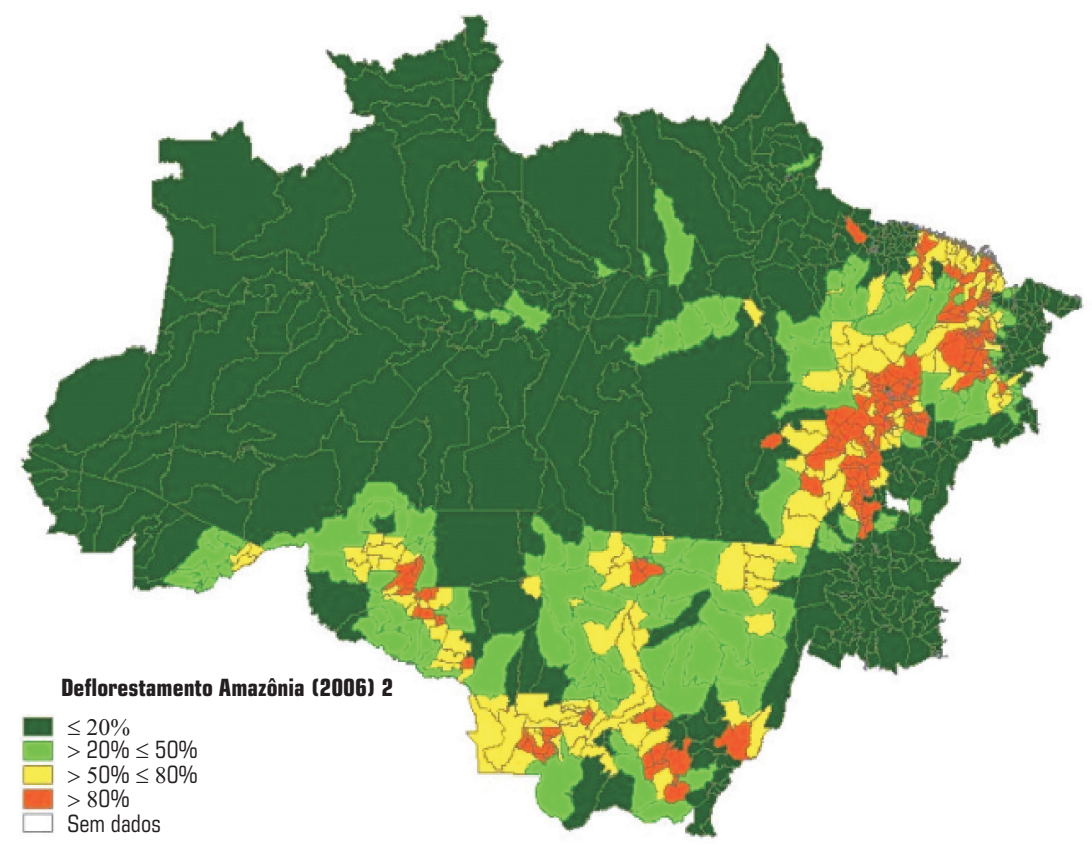

Fonte: INPE (2008) - Elaboração dos Autores.

Como era de se esperar, os municípios que estão na chamada "fronteira consolidada do desmatamento" são aqueles que têm a maior participação na faixa de desmatamento acima de $50 \%$. Na verdade, em 2000 (Figura 1), todos os municípios com áreas desmatadas acima de 50\% da área de não floresta se encontravam no chamado "arco do desmatamento". Os Estados do Pará, do Mato Grosso, de Rondônia, do
Maranhão e de Tocantins concentram o maior número de municípios com áreas desmatadas acima de $80 \%$. O Sudeste $\mathrm{Pa}$ raense, o Sul do Mato Grosso, o Centro de Rondônia, o Leste do Maranhão e o Norte do Tocantins têm a maior parte da sua área já desmatada. Esses municípios correspondem às regiões onde os processos de ocupação da fronteira foram mais intensos a partir da década de 1970 e são também as 
áreas onde se concentra a maior parte da população que está fora dos grandes centros urbanos.

Uma mudança significativa dos dados de 2000 para 2006 é a expansão do desmatamento para as áreas no entorno dos municípios que têm a maior intensidade de ocupação (Figura 2). As zonas onde aumentam os municípios que têm de $20 \%$ a menos de 50\% de área desmatada ocorrem principalmente no entorno das zonas já consolidadas. A exceção dessa regra é a expansão registrada na região Norte do Mato Grosso, no entorno da BR-163, que tem aumento da expansão das áreas desmatadas nos municípios. Essa expansão, fora do entorno das zonas da chamada "fronteira consolidada", é um importante resultado para direcionar uma análise mais precisa dos processos de desmatamento. Tais processos, neste caso, não parecem estar associados apenas à expansão das áreas ocupadas da Amazônia para atividades tradicionais, mas parecem confirmar a expectativa de que a expansão das zonas de produção agropecuária de larga escala amplia e intensifica os processos de desmatamento.

É importante notar que os municípios do Pará e do Amazonas, onde está ocorrendo parte do desmatamento com taxas mais altas, têm, em geral, áreas totais muito grandes, o que certamente reduz o impacto desse tipo de análise. Os processos de intensificação da denominada "fronteira consolidada", porém, parecem ir a contrapelo da ideia de que essa intensificação reduz os impactos da expansão sobre novas áreas. Isto é, ao que parece, o processo de desmatamento analisado aqui confirma a ideia de que novos cultivos e novas áreas de expansão da agropecuária de larga escala reforçam as dinâmicas de desmatamento existentes. Seja pelo financiamento da expansão da pecuária baseando-se nos processos de arrendamento de áreas antigas, capitalizando os pecuaristas para financiar a expansão das pastagens em terras de menor valor, seja aumentando as expectativas de valorização das terras novas ocupadas em áreas próximas das zonas de expansão da agricultura de larga escala, intensificando o desmatamento associado a motivos especulativos.

Observando-se, então, a espacialidade dos processos de expansão do desmatamento, pode-se perceber que, a despeito de uma potencial difusão espacial associada a fatores logísticos (como novas estradas, asfaltamento e custos de transporte menores), há ainda fatores endógenos associados à expectativa de rentabilidade dos agentes sobre os investimentos em ampliação das áreas ocupadas com novos cultivos específicos. Esses processos de decisão dos agentes pre- 
cisam ser mapeados e reconhecidos, caso se queira produzir políticas efetivas de redução do desmatamento na Amazônia.

\section{As causas diretas do desmatamento na Amazônia Legal}

Para identificar as causas diretas do desmatamento da Amazônia, foi construído um banco de dados que combinava diversas fontes. Foram coletados os dados do Prodes (INPE, 2008) de identificação dos dados de desmatamento da Amazônia Legal brasileira (área desmatada de floresta), ${ }^{2}$ o número de cabeças bovinas de 782 municípios da Amazônia da Pesquisa Pecuária Municipal (IBGE, 2008), a área plantada de culturas perenes e temporárias selecionadas nos mesmos municípios da Produção Agrícola Municipal do Sidra (IBGE, 2008). O número de 782 municípios foi estabelecido valendo-se da combinação dos municípios dos Estados do Acre, do Amazonas, de Rondônia, de Roraima, do Amapá, do Pará, de Tocantins, do Mato Grosso e do Maranhão. Os dados do IBGE foram combinados com os dados do Prodes, sendo, assim, alguns municípios dos Estados do Maranhão (23) e do Mato Grosso (2) (não incluídos na listagem do INPE) foram, portanto, eliminados.

\subsection{Uso do solo \\ e desmatamento}

A pecuária bovina é a atividade mais fortemente correlacionada com desmatamento para os municípios da Amazônia. $\mathrm{Na}$ análise que inclui apenas a pecuária bovina, encontrou-se um coeficiente de correlação de 0,7345 entre o número de cabeças de gado e o desmatamento (Tabela 2). Observando-se as correlações, percebese baixa correlação entre a variável soja e o desmatamento. Isso sugere que a fraca correlação direta da soja com os processos de desmatamento implica o pouco impacto desse tipo de cultivo sobre a ocupação de novas áreas na Amazônia. Observando-se, porém, as correlações entre soja e $\operatorname{arroz}(0,6462)$ e soja e milho $(0,7397)$ e entre arroz e desmatamento $(0,3562)$ e entre milho e desmatamento (0.2235), vê-se que soja e desmatamento podem estar ligados de forma indireta. Arroz e milho são culturas associadas ao processo de implantação da cultura de soja em áreas novas. Observações de campo feitas pelos autores demonstram que é comum plantar-se arroz em áreas novas por aproximadamente 3 anos antes de se iniciar a produção de soja.
2 Para os dados de desmatamento, foi escolhida a área desmatada total por município a partir de 2000. 
Tabela 2_Coeficientes de correlação, usando todas as observações (2000-2006)

\begin{tabular}{c|c|c|c|c|c|c|c}
\multirow{2}{*}{ desm } & bovino & soja & arroz & milho & perm & temp_sem_gr & \\
\hline 1,0000 & 0,7345 & 0,0864 & 0,3562 & 0,2235 & 0,2850 & 0,1181 & desm \\
\hline & 1,0000 & 0,0357 & 0,1980 & 0,1186 & 0,2692 & 0,0825 & bovino \\
\hline & 1,0000 & 0,3541 & 0,7397 & $-0,0296$ & 0,6462 & soja \\
\hline & & 1,0000 & 0,3640 & 0,0357 & 0,1874 & arroz \\
\hline
\end{tabular}

Fonte: INPE (2008) e IBGE (2008).

Nota: $5 \%$ valor crítico $($ bilateral $)=0,0265$ para $\mathrm{n}=5474$

Essas relações entre arroz, milho e soja são ainda mais importantes quando se observam os resultados das regressões efetuadas. Com uma regressão simples de mínimos quadrados ordinários que, utilizando a variável número de cabeças como termo independente, se tem o desmatamento como variável dependente. $\mathrm{O}$ desmatamento, nesse modelo, tem um $\mathrm{R}^{2}$ ajustado de 0,5397 (erro 0.0077166) e um coeficiente beta de 0,4048625 . Os resultados dessa regressão demonstram que o principal componente da variação do desmatamento é a pecuária, explicando $\sim 54 \%$ a sua variação. A pecuária bovina, então, é, individualmente, a principal causa imediata do desmatamento da Amazônia, o que é consistente com a lite- ratura sobre desmatamento da Amazônia revisada aqui.

Analisou-se a relação do desmatamento com a pecuária em três momentos, 2000, 2003 e 2006. Para o ano 2000, a correlação foi de 0,6808; em 2003, de 0,7060; e em 2006, de 0,7768. Percebe-se claramente o aumento considerável da relação com o passar do tempo. A soja, embora tenha correlação muito baixa (no máximo 0,1030), mostra um crescimento relativo desses valores no decorrer do tempo. Tal cenário só reforça a hipótese já discutida de que a pecuária bovina é a principal causa imediata do desmatamento e que tal tendência tende a aumentar. 
Tabela 3_Correlações entre cabeças bovinas, soja e desmatamento

\begin{tabular}{l|c|c|c|c|c|c|c}
$\ldots \ldots$ & $\ldots \ldots$ & $\ldots$ & $\ldots$ & $\ldots$ & $\ldots$ \\
Ano & $\mathbf{2 0 0 0}$ & $\mathbf{2 0 0 1}$ & $\mathbf{2 0 0 2}$ & $\mathbf{2 0 0 3}$ & $\mathbf{2 0 0 4}$ & $\mathbf{2 0 0 5}$ & $\mathbf{2 0 0 6}$ \\
\hline Corr. Bovino & 0.6808 & 0.6920 & 0.7007 & 0.7060 & 0.7557 & 0.7629 & 0.7768 \\
\hline Corr. Soja & 0.0522 & 0.0481 & 0.0650 & 0.0773 & 0.0981 & 0.0978 & 0.1030 \\
$\ldots \ldots \ldots$
\end{tabular}

Fonte: Elaboração dos autores.

Com base nesses resultados, podese ver que os processos estruturais que correlacionam pecuária e desmatamento, longe de reduzirem seu impacto, estão ampliando seu peso no desmatamento. A correlação da soja com o processo de desmatamento, vista assim para a Amazônia toda, parece ser extremamente baixa, o que, em princípio, não justificaria a afirmativa de que há relação direta entre a expansão dos cultivos de soja e os processos de desmatamento na Amazônia. Isso não é bem o caso; na próxima seção, ampliar-se-á a análise utilizando-se de regressões para interpretar melhor a relação entre os usos do solo e o desmatamento da Amazônia.

\section{2_Regressões em seção cruzada e com dados em painel}

Para a análise dos dados de regressão, foram utilizados dados em painel para os referidos 782 municípios dos Estados da Amazônia Legal que combinavam com a lista de municípios do INPE. O período dos dados utilizados no painel foi anual e abrange os anos de 2000 a 2006. Esse conjunto de dados perfaz 5.474 observações. O uso de dados em painel se justifica pelo fato de essa combinação de dados permitir maior nível de informação, variabilidade e eficiência no uso dos dados, bem como menor colinearidade (Gujarati, 2006). Foram utilizados efeitos fixos nas regressões, visto que os testes de Durbin-Watson para as regressões foram significativamente próximos de 2 , implicando baixa autocorrelação nos modelos.

Foram testadas duas classes de modelos. Num primeiro momento, foi feito um modelo de seção cruzada anual para anos específicos. Foram testadas as causas diretas do desmatamento nos anos de 2000, 2003 e 2006. A segunda classe de modelo foi a regressão em painel propriamente dita. Foram feitas regressões para os Estados de maior taxa histórica de desmatamento anual (Mato Grosso, Pará e Rondônia) e também para o Estado do Amazonas, que 
3 Variáveis: desm - Hectares de Desmatamento; perm Área Plantada (HA) de culturas permanentes; arrozÁrea Plantada (HA) de arroz; milho - Área Plantada (HA) de milho; soja - Área Plantada (HA) de soja; temp_sem_gr Área Plantada (HA) de culturas temporárias, excluindo arroz, milho e soja; bovino - Número de cabeças de gado bovino. é o maior Estado da região. Todos os modelos testados neste trabalho têm o desmatamento como variável dependente.

$\mathrm{Na}$ primeira classe de modelos, procurou-se observar a relação direta entre as variáveis de uso do solo e o desmatamento dentro de um dado ano. Na segunda classe de modelos, foram feitas regressões em painel para os dados de desmatamento dos principais Estados. As classes de modelos testadas foram:

\section{Classe de Modelo $1^{3}$ (seção cruzada anos 2000, 2003, 2006)}

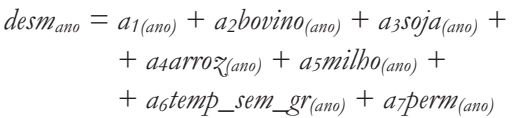

Classe Modelo 2 (painel 2000-2006 total e Estados de MA, PA, RO e AM)

desm_estado $=a_{1}+a_{2}$ bovino $+a_{3}$ soja + a4arroz + + asmilho $+a_{6}$ temp_sem_gr + a7perm

Quando são feitas as regressões com as seções cruzadas (Tabela 4), nota-se, para todos os anos, uma relação negativa entre a soja e o desmatamento. Essa relação é significativa para 2000 e 2003 e não significativa para 2006. A relação negativa da soja com desmatamento não é, obviamente, associada a alguma propriedade "conservacionista" da soja, mas provavelmente está associada ao fato de que os municípios onde a soja ocorre normalmente já estão nos seus ciclos finais de ocupação, tendo, portanto, poucas áreas novas disponíveis para a expansão dos cultivos agropecuários. Nas regressões, não foi possível verificar esse efeito, portanto não há como estabelecer conexão direta entre as áreas disponíveis nos municípios e o desmatamento eventualmente associado à soja.

O fato marcante do modelo é ainda, como se poderia esperar, o peso da pecuária nos diversos anos. A observação dos resultados do modelo aponta para um aumento da participação da pecuária na expansão das áreas desmatadas. A pecuária, nesta análise, portanto, permanece a atividade que, individualmente, tem mais peso no processo de desmatamento.

Quando se estabelece a análise com dados em painel numa série de 2000 para 2006 (Tabela 5), há uma mudança significativa na participação dos diversos usos do solo nos resultados das regressões.

A relação da soja com o desmatamento passa a ser positiva e significativa para quase todos os cortes efetuados, à exceção do Amazonas. Embora a pecuária continue sendo o coeficiente mais importante da equação de regressão para qualquer aspecto da análise, a soja passa a ter importância significativa na regressão para a Amazônia com um todo. 
Tabela 4_Causas diretas do desmatamento - MQO por ano

\begin{tabular}{|c|c|c|c|c|c|c|c|c|}
\hline Ano/R ${ }^{2}$ & & bovino & soja & arroz & milho & temp_sem_gr & perm & _cons \\
\hline 2000 & coef & 0.5602 & -0.8172 & 3.7420 & 2.1137 & 1.3212 & 3.4571 & 13339.5800 \\
\hline $\mathrm{R}^{2}$ & std err & 0.0279 & 0.1477 & 0.6188 & 0.5985 & 0.7651 & 1.1137 & 2906.7750 \\
\hline 0.53 & $\mathrm{P}>\mathrm{t}$ & 0.000 & 0.000 & 0.000 & 0.000 & 0.085 & 0.002 & 0.000 \\
\hline 2003 & coef & 0.5813 & -0.4927 & 7.3986 & 2.0306 & 1.1222 & 5.2000 & 8628.1320 \\
\hline $\mathrm{R}^{2}$ & std err & 0.0232 & 0.1253 & 0.7113 & 0.5130 & 0.6795 & 1.1943 & 3419.8270 \\
\hline 0.59 & $\mathrm{P}>\mathrm{t}$ & 0.000 & 0.000 & 0.000 & 0.000 & 0.099 & 0.000 & 0.012 \\
\hline 2006 & coef & 0.6683 & -0.0727 & 10.2931 & 1.7142 & -0.4048 & 4.6548 & 2541.5640 \\
\hline $\mathrm{R}^{2}$ & std err & 0.0209 & 0.1223 & 1.1830 & 0.5366 & 0.5729 & 1.3021 & 3716.0100 \\
\hline 0.65 & $\mathrm{P}>\mathrm{t}$ & 0.000 & 0.552 & 0.000 & 0.001 & 0.480 & 0.000 & 0.494 \\
\hline
\end{tabular}

Fonte: Elaboração dos autores.

Tabela 5_Causas diretas do desmatamento - Painel 2000-2006

\begin{tabular}{|c|c|c|c|c|c|c|c|c|}
\hline$U F / R^{2}$ & & bovino & soja & arroz & milho & temp_sem_gr & perm & cons \\
\hline Amazônia & coef & 0.3857 & 0.6437 & -0.0201 & -0.9629 & -0.3462 & 0.2204 & 44995.8300 \\
\hline $\mathrm{R}^{2}$ & std err & 0.0078 & 0.0368 & 0.1091 & 0.1076 & 0.1504 & 0.4897 & 927.2544 \\
\hline 0.49 & $P>t$ & 0.000 & 0.000 & 0.854 & 0.000 & 0.021 & 0.653 & 0.000 \\
\hline Amazonas & coef & 0.2932 & 9.1309 & 0.7565 & 7.6169 & 0.7975 & -1.8723 & 40482.1900 \\
\hline $\mathrm{R}^{2}$ & std err & 0.03777 & 14.29960 & 1.51067 & 1.98827 & 0.46966 & 1.05869 & 1396.95100 \\
\hline 0.3 & $P>t$ & 0.000 & 0.524 & 0.617 & 0.000 & 0.090 & 0.078 & 0.000 \\
\hline Rondônia & coef & 0.3120 & 1.6380 & -1.0503 & -1.3479 & 11.1486 & 3.3570 & 52553.0400 \\
\hline $\mathrm{R}^{2}$ & std err & 0.01532 & 0.51684 & 1.02775 & 1.14530 & 1.51875 & 0.94644 & 5480.64800 \\
\hline 0.56 & $P>t$ & 0.000 & 0.002 & 0.308 & 0.240 & 0.000 & 0.000 & 0.000 \\
\hline Pará & coef & 0.4200 & 3.9435 & 0.0941 & -2.1844 & -0.4155 & -0.8812 & 90023.0600 \\
\hline $\mathrm{R}^{2}$ & std err & 0.01875 & 0.93283 & 0.42083 & 0.43458 & 0.75001 & 1.21819 & 3250.48700 \\
\hline 0.68 & $\mathrm{P}>\mathrm{t}$ & 0.000 & 0.000 & 0.823 & 0.000 & 0.580 & 0.470 & 0.000 \\
\hline Mato Grosso & coef & 0.3472 & 0.5319 & 0.1612 & -0.3394 & -0.1695 & -0.3400 & 51786.0300 \\
\hline $\mathrm{R}^{2}$ & std err & 0.0200 & 0.0400 & 0.1400 & 0.1400 & 0.1900 & 1.0100 & 3514.9800 \\
\hline 0.31 . & $P>t$. & 0.000 & 0.000 . & 0.270 & 0.020 . & 0.370 . & 0.740 & 0.000 \\
\hline
\end{tabular}

Fonte: Elaboração dos autores. 
Arroz, milho e outras culturas temporárias (que excluem arroz, milho e soja) têm coeficientes negativos na regressão para a Amazônia com um todo, mas a participação do arroz na regressão não se mostrou significativa em praticamente nenhum corte analisado. As diferenças entre os coeficientes dos diversos usos nos cortes efetuados na regressão parecem demonstrar diferenças estruturais que vão se refletir na participação de cada uso nas equações. Essas diferenças estruturais resultam de processos concretos de ocupação e uso do solo que podem ser associados a padrões de ocupação e, consequentemente, a atividades que se refletem na participação de cada uso deste na expansão das áreas desmatadas. Tais processos vão refletir-se também nas dinâmicas espaciais de expansão da ocupação que, longe de refletir apenas fatores logísticos ou processos de difusão das atividades espacialmente conectadas (como a expansão dos cultivos existentes ou a abertura de novas áreas de pastagem dentro das propriedades), resultam de processos de tomada de decisão dos agentes sobre investimento e da expectativa de valorização do capital associada à ocupação de novas terras na fronteira.

Guardando-se a importância desses processos endógenos de expansão do desmatamento (que ocorrem nas áreas conso- lidadas), é necessário ver que, nas áreas de expansão das atividades agropecuárias, as decisões dos agentes sobre sua ocupação vão ocorrer motivadas por expectativas de renda (seja ela associada à valorização da terra, seja ela associada à atividade produtiva), por fatores associados à disponibilidade de capital, bem como por fatores associados ao conhecimento e à cultura em determinadas atividades.

Nesse sentido, o aumento da importância da soja como uso do solo associado ao processo de desmatamento é significativo. A ocupação de novas áreas pela soja, quando se analisa a regressão com os dados em painel, parece produzir um efeito de reforço às atividades já existentes associadas à grande produção, mais especificamente, à pecuária. Isso está fortemente relacionado ao fato de que a disponibilidade de áreas agricultáveis para culturas de larga escala implica, provavelmente, a realocação de atividades já existentes, como pastagens e outros cultivos temporários ou permanentes. Essas atividades, financiadas pela valorização da terra ou pelo influxo de capital do arrendamento e ou venda das terras na fronteira sul e oriental da Amazônia, provavelmente migrarão para áreas mais no interior da região, ampliando assim os impactos da ocupação da Amazônia pela produção agropecuária altamente capitali- 
zada. Esses efeitos derivados da expansão da agricultura de larga escala são difíceis de identificar e de medir, mas os resultados observados nas regressões em painel parecem demonstrar que os processos de ocupação e uso do solo pela agricultura de larga escala reforçam as dinâmicas de expansão.

Um aspecto que ainda é necessário identificar é a participação da pequena produção agropecuária na expansão do desmatamento. As culturas temporárias não associadas à agricultura de larga escala, como mandioca e feijão, têm reduzido sua área nas regiões de ocupação da pequena produção. A participação das culturas permanentes no total do uso do solo é sempre uma parte muito pequena do uso do solo total; isso implica que a expansão das áreas das culturas temporárias, caso ocorra, vai ter pequeno impacto na expansão de processos de desmatamento. A pecuária, no entanto, tem presença grande também na pequena produção e é o principal uso do solo associado a essas propriedades. Isso resulta que eventuais aumentos nas expectativas de renda associadas à pecuária podem ter impactos tanto na grande como na pequena propriedade na Amazônia. Isto é, o aumento de expectativa de rentabilidade da atividade pecuária tende a ter efeitos sistêmicos muito mais amplos e, provavelmente, implicará grande impacto nas taxas de desmatamento.
O papel da pecuária no processo de desmatamento e na consequente emissão de carbono também torna urgente a elaboração de políticas específicas para a atividade na Amazônia a fim de reduzir, de alguma forma, os impactos de sua forte expansão sobre a floresta. Antes de ir às políticas, porém, é necessário entender melhor a nova dinâmica econômica que modifica a atividade. Não há apenas uma pecuária na Amazônia; há várias formas diferentes de organização da atividade pecuária que não são nem contraditórias nem excludentes na fronteira. $\mathrm{Na}$ fronteira de expansão da ocupação da Amazônia por atividades produtivas, é possível encontrar pecuaristas completamente articulados com a nova dinâmica de expansão da agricultura de larga escala e agindo (tomando decisões de investimento) coerentemente com esse movimento.

\section{5_O papel e a extensão da pecuária na Amazônia}

A atividade pecuária está presente tanto nas pequenas propriedades quanto nas grandes e tem se expandido quase continuamente em toda a história recente da ocupação da região. Os processos associados à expansão da pecuária têm se mostrado, portanto, extremamente resilientes; isso se dá não por uma causa única, como a rentabilidade específica da ativi- 
dade, mas é o resultado da interação complexa de múltiplas causas (Pikkety et al., 2003; Rodrigues, 2004). Essas causas estão associadas, principalmente, à liquidez da atividade, à relativa simplicidade dos processos produtivos, bem como ao baixo nível de investimento de capital necessário à sua instalação. A pecuária está presente tanto na fronteira mais antiga quanto nas zonas de expansão da ocupação da floresta. É uma atividade que, pela sua importância na participação da ocupação, necessita de análises mais precisas, bem como de políticas públicas específicas para o seu desenvolvimento e também para a redução do seu impacto na fronteira do desmatamento.

Um movimento recente vem aumentando o peso da pecuária na Amazônia Legal. De 1990 a 2006, o rebanho bovino cresceu a uma taxa de $6,74 \%$ ao ano ${ }^{-1}$, na região, enquanto no resto do Brasil o crescimento médio do rebanho foi de $0,57 \%$ ao ano $^{-1}$. Com essas taxas, segundo os dados da Pesquisa Pecuária Municipal do IBGE, o rebanho cresceu de 26 milhões de cabeças em 1990 para 73,7 milhões em 2006, mais de 180\% em 16 anos.

Essa expansão acompanha o crescimento da demanda interna e externa de carne bovina, mas também é influenciada por outros fatores, como a sucessiva redução de custos de transporte, o aumento da produtividade da atividade associado a uma maior eficiência no manejo e o ainda relativamente pequeno preço da terra nas regiões de expansão da Amazônia. A maior parte do crescimento do rebanho brasileiro (de 26 milhões em 1990 para 73,7 milhões em 2006), ${ }^{4}$ mais de 180\% em 16 anos, deu-se nos Estados da Amazônia brasilei$\mathrm{ra}$, mais especificamente naqueles onde o desmatamento é maior (Mato Grosso, Pará e Rondônia). Esse avanço da pecuária sobre as novas áreas segue uma dinâmica que está associada ao aumento da demanda de carne e à progressiva integração da pecuária da região com mercados globalizados.

\section{Causas subjacentes da expansão da pecuária na Amazônia Legal}

Os dados do Conselho Nacional da Pecuária de Corte (ABIEC, 2007) demonstram que o consumo de carne no Brasil tem crescido nos últimos anos. Embora as exportações apresentem uma taxa de crescimento média mais alta ( $17 \%$ ao ano), o consumo interno tem crescido em torno de 3\% em média ao ano. Mesmo com esse crescimento, as exportações de carne ainda são bem menores que os níveis de consumo interno, ou seja, representam em torno de $32 \%$ do consumo interno de carne bovina do Brasil. No ano de 2006, a demanda interna era de quase 7
4 Pesquisa Pecuária

Municipal (IBGE, 2008). 
milhões de toneladas equivalentes de carcaça (TEC), e as exportações perfaziam menos de 2,5 milhões de toneladas equivalentes de carcaça (ABIEC, 2007). Isso implica que, mesmo mantendo taxas mais baixas de crescimento, como mostram as projeções lineares da Figura 3, se pode estimar que a demanda interna alcance, no ano de 2012, em torno de 7,5 milhões de TEC, ao passo que a demanda externa ficará pouco abaixo de 3 milhões de TEC.

Sendo as restrições ao consumo de carne em áreas ainda não liberadas pela Organização Mundial de Sanidade Animal (OIE) menos impactantes no nível interno, é de se esperar que a carne produzida internamente nas regiões ainda não declaradas áreas livres de aftosa continue sendo consumida no mercado brasileiro, que é em torno de $70 \%$ da demanda total. As implicações dessa expansão são grandes. O crescimento da demanda interna de carne não é reduzido pelas restrições sanitárias internacionais. Isso implica que, se as tendências de crescimento econômico estável se confirmarem, haverá a manutenção das taxas de aumento do consumo interno de carne bovina no Brasil.

As exportações brasileiras de carne se concentram nos portos do Sul e do Sudeste do Brasil. A maior parte da carne exportada em 2006 (mais de US\$ $2.93 \mathrm{mi}$ - lhões) saiu pelo porto de Santos, em São Paulo. Essa significativa concentração não reflete, necessariamente, a participação do rebanho paulista no total nem se reflete no crescimento da participação de São Paulo ou dos outros Estados do Sudeste-Sul no abate animal (ABIEC, 2007).

Ao separar-se nas estatísticas de abate os Estados da Amazônia Legal brasileira, vê-se que o crescimento do abate de bovinos se deu quase todo nessa região. Somente nela esse tipo de abate cresceu consistentemente de 2004 até 2007, o que é acompanhado pela expansão dos frigoríficos para a região Amazônica, mais especificamente para a região Sul e Oeste da Amazônia brasileira (Figura 4).

$\mathrm{Na}$ Associação Brasileira da Indústria de Carne (ABIEC, 2007), estão listadas as unidades produtivas dos frigoríficos membros. Os dois principais frigoríficos, que têm 31 das 87 unidades produtivas listadas, concentram suas operações em São Paulo, nos Estados do Centro-Oeste, em Rondônia, no Tocantins, no Acre e no Pará. O frigorífico Margem, por exemplo, mantém dois entrepostos em São Paulo. Os Estados do Mato Grosso e de Rondônia se destacam como os maiores em números de frigoríficos filiados na ABIEC, presentes na Amazônia Legal. 
Figura 3_ Brasil: consumo interno e exportações de produtos da pecuária bovídea

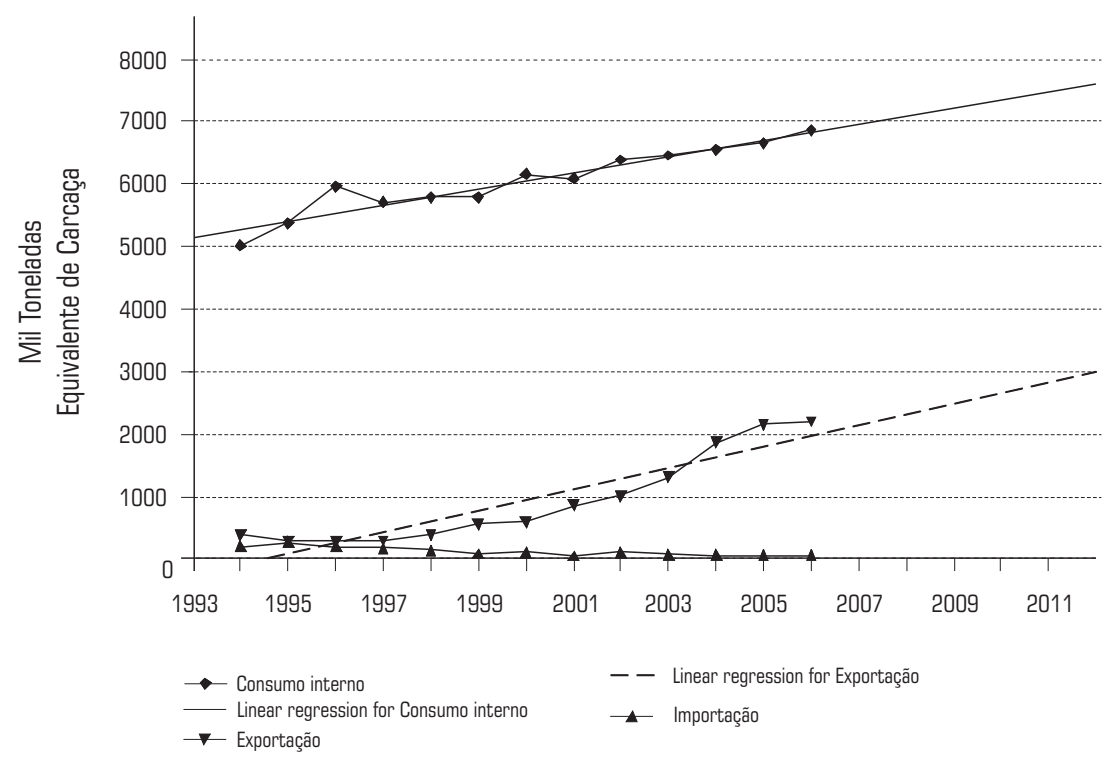

Fonte: ABIEC (2007).

Tabela 6_Balanço da Pecuária Bovina - 1994 a 2006

\begin{tabular}{|c|c|c|c|c|c|c|c|c|c|c|c|c|c|}
\hline & 1994 & 1995 & 1996 & 1997 & 1998 & 1999 & 2000 & 2001 & 2002 & 2003 & 2004 & $2005^{a}$ & $2006^{b}$ \\
\hline Consumo interno & 5018 & 5376 & 5962 & 5710 & 5797 & 5793 & 6158 & 6091 & 6395 & 6463 & 6549 & 6660 & 6860 \\
\hline Exportação & 378 & 285 & 278 & 287 & 378 & 560 & 592 & 858 & 1006 & 1301 & 1854 & 2150 & 220 \\
\hline Importação & 196 & 262 & 196 & 177 & 135 & 83 & 100 & 49 & 101 & 64 & 53 & 60 & \\
\hline
\end{tabular}

Fonte dos dados básicos: SRF/MF, SECEX/MDIC, MAPA, EMBRAPA, IBGE, CNPC, Fórum Nacional Permanente da Pecuária de Corte - CNA, Sec. Estaduais de Agricultura.

Obs.: (a) Preliminar; (b) Estimativa; Em mil toneladas em equivalente carcaça. Rebanho: 1994 - PPM/IBGE; 1996 - Censo Agropecuário/IBGE; 1995 e 1997 a 2006 - Estimativas. 


\section{Figura 4_Brasil: Bovinos Abatidos 2000 a 2008}

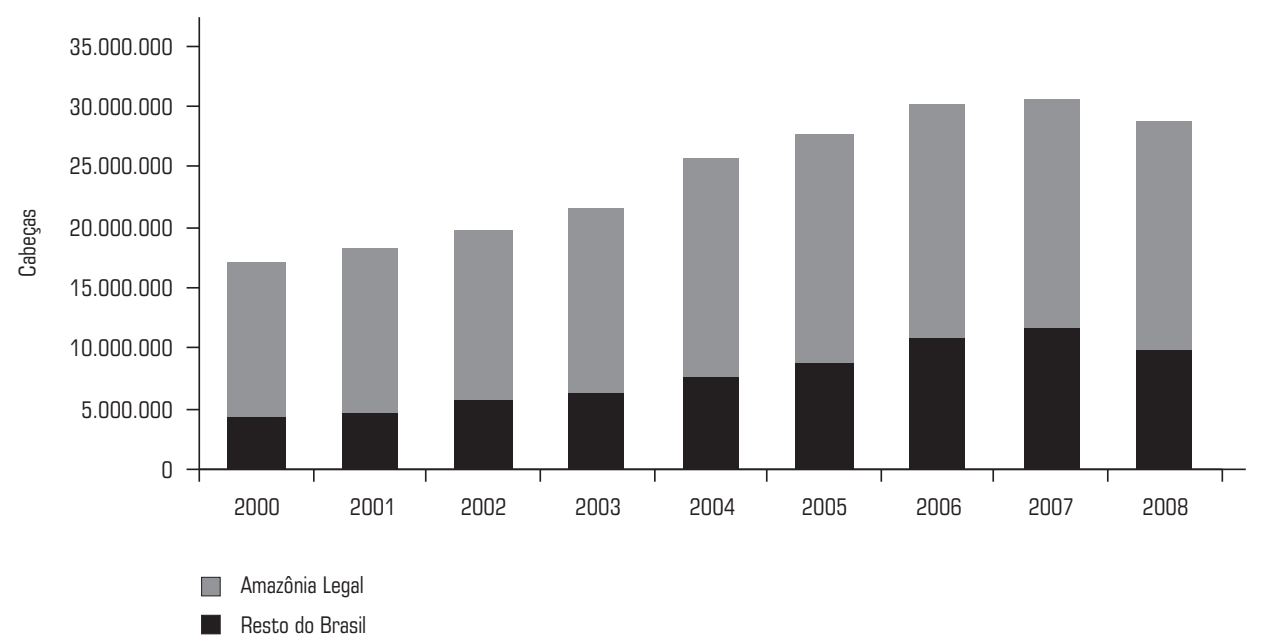

Fonte: IBGE, Pesquisa Trimestral de Abate de Animais (www.sidra.ibge.gov.br)

O movimento de expansão dos frigoríficos para a Amazônia reflete, por um lado, uma lógica de redução de custos de aquisição de matéria-prima e, por outro, um posicionamento em um mercado em expansão. As operações de exportação desses frigoríficos, se estiverem ocorrendo apenas com bovinos abatidos no Sudeste, estão reduzindo a oferta de carne para consumo interno. Essa redução poderia, então, estar sendo suprida por bovinos abatidos no Sul e no Leste da Amazônia. Além disso, o fim das barreiras sanitárias para a carne do Mato Grosso, de Rondônia e do Sudeste do Pará abre novos mercados de exportação. Se os custos da logística de transporte forem reduzidos, nada impede a ampliação da operação de exportação nos portos da Amazônia. Isso por si só não é necessário. A carne de bovinos abatidos nos frigoríficos que têm unidades de produção na Amazônia pode estar sendo resfriada ou congelada e exportada pelo porto de Santos. Tudo é uma questão de custo, demanda e logística. 
Figura 5_ Número de instalações de frigoríficos filiados à ABIEC por UF

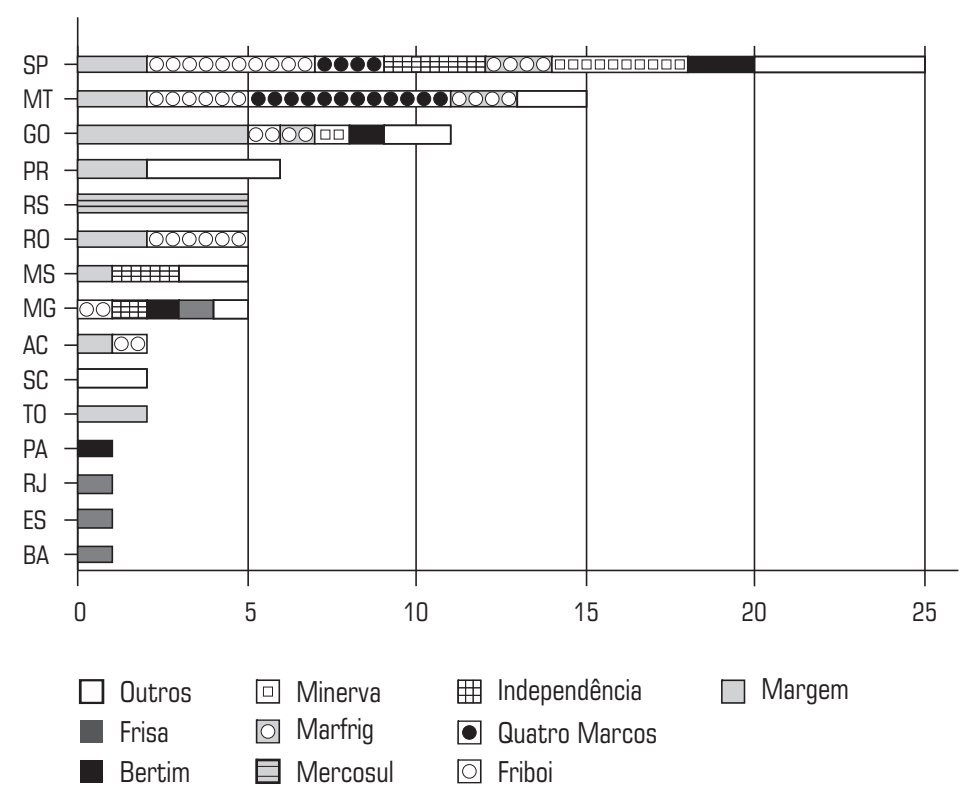

Fonte: ABIEC (2007).

Os frigoríficos brasileiros têm se posicionado nas regiões onde a pecuária está se expandindo. Essa região tem tido taxas de expansão significativamente superiores às do resto do Brasil. Apesar de o efetivo bovino das outras regiões do Brasil ainda ser maior, a pecuária tem se expandindo mais fortemente nos Estados da Amazônia Legal brasileira.

A participação do rebanho bovino da Amazônia Legal no total do rebanho brasileiro subiu de 17,85\% em 1990 para
36,01\% em 2005. Esse crescimento reflete a forte expansão da atividade pecuária nas áreas de expansão do desmatamento na Amazônia brasileira (Figura 6).

O crescimento da pecuária bovina na Amazônia brasileira tem sido, nos anos analisados, sempre bem maior que no resto do Brasil. Esse crescimento apresentou, de 2000 a 2005, uma taxa média anual de 7\% na Amazônia Legal, ao passo que, no resto do Brasil, a taxa média de crescimento ano a ano ficou em torno de 1\% (Figura 7). 


\section{Figura 6_Efetivo do Rebanho Bovino (1990-2005)}

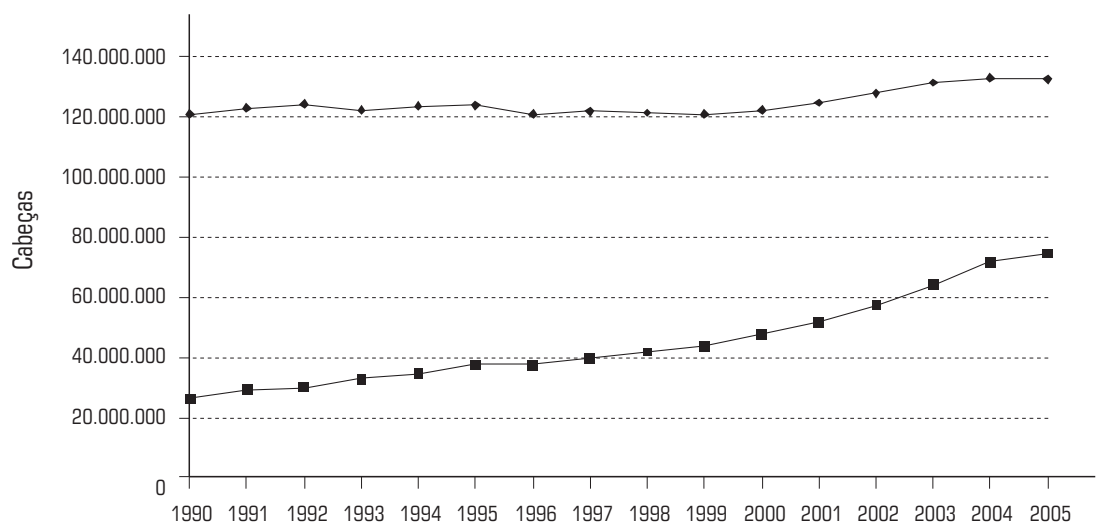

- Amazônia Legal

$\rightarrow$ Resto do Brasil

Fonte: IBGE - Produção Pecuária Municipal (http://www.sidra.ibge.gov.br).

\section{Figura 7_Brasil e Amazônia: Taxas de Crescimento Anual do Rebanho Bovino}

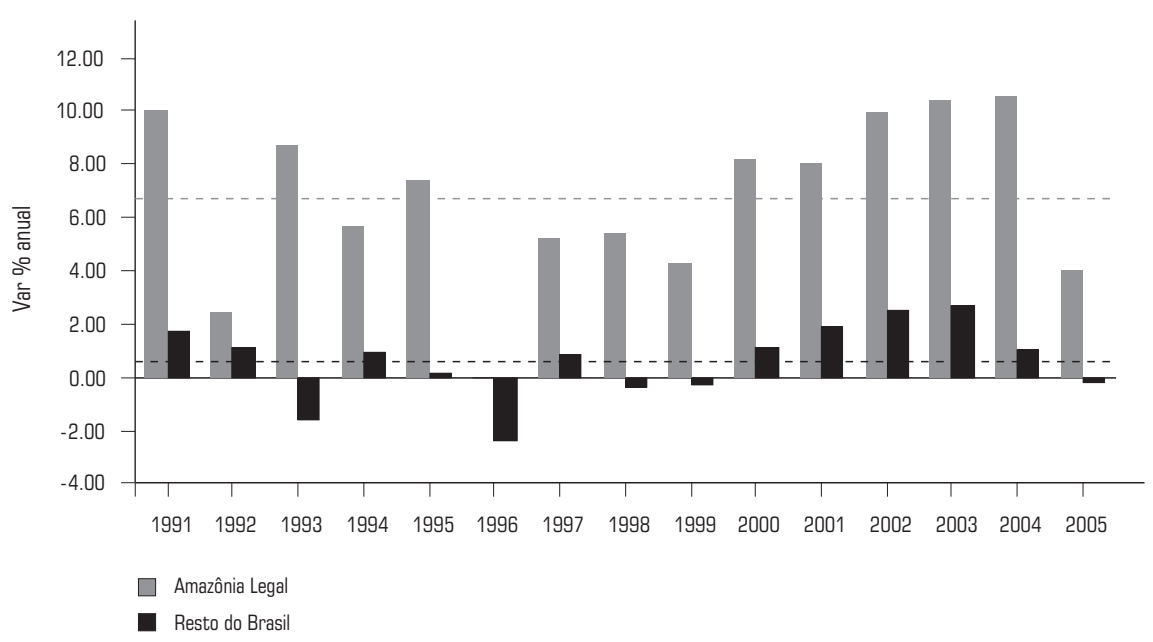

Fonte: IBGE - Produção Pecuária Municipal (http://www.sidra.ibge.gov.br) 
A forte expansão da pecuária bovina na Amazônia é uma tendência que deve continuar. Caso o atual quadro de demanda global continue em expansão, e a presença das instituições na fronteira amazônica continue frágil, o contexto institucional que permite a expansão da pecuária na fronteira vai continuar funcionando. Aliadas a isso, as novas demandas e a rentabilidade maior da pecuária na Amazônia vão reforçar esses processos de expansão.

Tais processos de expansão da atividade pecuária são reforçados ainda mais pela entrada de novos atores no jogo. A expansão da agricultura de larga escala e o potencial de ampliação dos usos do solo por novas culturas para a produção de bioenergia são, potencialmente, um processo que vai reforçar ainda mais a importância do papel da pecuária na expansão da fronteira do desmatamento.

\section{7_Conclusões e uma perspectiva para a política pública}

A pecuária bovina é o uso do solo mais importante em todos Estados da Amazônia. É uma atividade, que, em geral, tem apresentado crescimento em todos os Estados. Esses fatos tornam a criação de gado a atividade econômica de maior impacto em toda a região.
A pecuária bovina também está fortemente associada com o desmatamento da Amazônia, sendo sua causa imediata mais importante. As regressões realizadas neste trabalho mostram também que o crescimento da agricultura de larga escala, em vez de reduzir, amplia o impacto da pecuária sobre o desmatamento.

As motivações para o investimento na criação de gado na Amazônia continuarão ocorrendo. A pecuária exige baixos níveis de capital, pouco preparo para o solo e tem poucas restrições associadas a relevo e $\mathrm{a}$ áreas livres de troncos em florestas recentemente desmatadas. Esses fatores tornam a pecuária a atividade mais intensamente associada aos processos de desmatamento na maior parte da região. Tal fato ainda está associado à baixa densidade dos rebanhos na região. A criação de gado bovino, normalmente, é extensiva, contando com números normalmente em torno de uma $c a-$ beça.bectare $e^{-1}$.

Políticas para a pecuária devem considerar esses dois aspectos citados; a expansão da pecuária é a principal causa imediata do processo de desmatamento; a atividade é, em sua maior parte, extensiva com baixa densidade do rebanho.

Para reduzir os impactos da expansão da pecuária, é necessário agir para aumentar a intensificação da atividade. De- 
ve-se tomar cuidado, porém, para que isso não ocorra apenas em áreas onde fatores como o preço da terra, os níveis de capital e a proximidade dos mercados consumidores favoreçam o processo. É necessário agir sobre a lógica dessa expansão, reduzindo o seu avanço sobre novas áreas na Amazônia. Para isso, políticas que promovam o cuidado ambiental, como boas práticas dentro das propriedades e algum processo de qualificação do rebanho (assegurando sua procedência de áreas fora da região onde ocorrem novos desmatamentos), podem ser úteis.

É necessário também considerar as diferenças entre pequenos e grandes produtores na pecuária bovina. Na Amazônia brasileira, a pecuária bovina é uma atividade importante nas pequenas propriedades. Políticas para a pecuária têm, certamente, que considerar esse fato. Políticas de intensificação que funcionam para a grande propriedade que, eventualmente, exigem grande volume de capital podem ser uma forte barreira para o aumento da intensificação na pequena produção. Isso pode reduzir o impacto de políticas que favoreçam a intensificação para os pequenos produtores. Como dito, políticas de incentivo à intensificação, portanto, devem considerar as diferenças de escala entre pequenos e grandes produtores, estabelecendo, casualmente, condições diferenciadas para cada um.
As políticas de controle da expansão do desmatamento e de promoção de boas práticas também devem considerar as diferenças entre pequenos e grandes produtores. Essas diferenças não são pequenas e precisam ser identificadas para estabelecer qual o melhor formato de uma política para cada tipo de ator (pequenos ou grandes produtores). Associado a isso, é necessário também reduzir a motivação da expansão da pecuária nas áreas onde a propriedade da terra é incerta ou se encontra sobre o controle formal do governo (as chamadas áreas devolutas). Sem o aumento do grau de ordenamento sobre a propriedade da terra e do aumento da legalidade nas áreas ocupadas, a pecuária de baixa produtividade e baixo investimento de capital vai continuar fazendo parte da lógica de expansão da ocupação da terra na Amazônia. 


\section{Referências bibliográficas}

\author{
ABIEC. Associação Brasileira \\ das Indústrias Exportadoras \\ de Carne. Disponível em: \\ $<$ http://www.aiec.org.br>. \\ Acesso em: 3 jul. 2007.
}

ALENCAR, A.; NEPSTAD, D.; MOUTINHO, P. Carbon emissions associated with forest fires in Brazil. In: MOUTINHO, P.; SCHWARTZMAN, S. (Ed.).

Tropical deforestation and climate change. Belém - Pará - Brazil: IPAM - Instituto de Pesquisa Ambiental da Amazônia; Washington DC - USA: Environmental Defense. 2005.

ALENCAR, A.; NEPSTAD, D.; MOUTINHO, P. Carbon emissions associated with forest fires in Brazil. In: MOUTINHO, P.; SCHWARTZMANN, S.

Tropical Deforestation and Climate Change. Belém: IPAM, 2005.

ALMEIDA, O. T. ; UHL, Christopher. Planejamento do uso do solo do município de Paragominas. Belém: Imazon, 1998. (Série Amazônia, 9).

ANDERSEN, E.; REIS, E. Deforestation and government policy in the Brazilian Amazon: an econometric analysis. IPEA,1997. (Texto para discussão, 513).
ANDERSEN, L. E.; GRANGER, C. W. J.; REIS, E. J.;

WEINHOLD, D.; WUNDER, S. The dynamics of deforestation and economic growth in the Brazilian Amazon. Cambridge University Press, 2002.

ARIMA, E.; BARRETO, P.; BRITO, M. Pecuária na Amazônia: tendências e implicações para a conservação ambiental. Belém: Instituto do Homem e Meio Ambiente da Amazônia, 2005.

DeFRIES, R. S.; HOUGHTO, R. A.; HANSEN, M. C.; FIELD, C. B.; SKOLE, D.; TOWNSHEND, J. Carbon emissions from tropical deforestation and regrowth based on satellite observations for the 1980s and 1990s. Proceedings of the National Academy of Sciences of the United States of America, n. 99, p. 14256-14261, 2002.

FEARNSIDE, P. Desmatamento e desenvolvimento agrícola na Amazônia brasileira. In: LÉNA, P.; OLIVEIRA, A. E. (Org.). Amazônia: a fronteira agrícola 20 anos depois. 2. ed. Belém:

CEJUP: Museu Paraense Emílio Goeldi, 1992.

FEARNSIDE, P. M. A Floresta Amarônica nas mudanças globais. Manaus, AM: Instituto Nacional de Pesquisas da Amazônia-INPA, 2003. 134 p.
FERRAZ, C. M. Measuring the causes of deforestation, agriculture, land conversion and cattle rancbing growth: evidence from the Amazon. IPEA, 2000. Draft.

FERREIRA, Leandro Valle; VENTICINQUE, Eduardo; ALMEIDA, Samuel. O desmatamento na Amazônia e a importância das áreas protegidas. Estudos Avançados, n. 19, p. 53, 2005.

FAOSTAT. Food and agriculture organization of the United Nations - Disponível em: $<$ http://faostat.fao.org/>. Acesso em: fev. 2008.

GEIST, H.; LAMBIN, E. What drives tropical deforestation? A meta analisys of proximate and undeliyng causes of deforestation based on subnational case study evidence. LUCC International Project Office, Louvain-la-neuve Belgium, 2001.

GEIST, H. J.; LAMBIN, E. F.

Proximate Causes and Underlying Driving Forces of Tropical Deforestation. BioScience, v. 52, p. 143-150, 2002.

GUJARATI, D. M. Econometria básica. São Paulo: Campus/

Elsevier, 2006.
HOUGHTON, R. Tropical deforestation as a source of greenhouse gas emissions. In: MOUTINHO, P.; SCHWARTZMAN, S. (Ed.) Tropical deforestation and climate change - Belém - Pará - Braquil: IPAM - Instituto de Pesquisa Ambiental da Amazônia; Washington DC - USA: Environmental Defense, 2005.

IBGE. Pesquisa trimestral de abate de animais. Brasília: IBGE, 2008. Disponível em: $<$ http://www.sidra.ibge.gov.br>

IBGE. Pesquisa pecuária municipal. Brasilia: IBGE, 2008. Disponível em: <http://www.ibge.gov.br>.

IBGE. Produção agrícola municipal. Brasília: IBGE, 2008. Disponível em: <http://www.ibge.gov.br>.

IBGE. Censo Agropecuário 1996. Brasília: IBGE, 2008. Disponível em: <http://www.ibge.gov.br>.

INPE. Instituto Nacional de Pesquisas Espaciais. Prodes desflorestamento nos municípios da Amazônia Legal. 2008. Disponível em: $<$ http://www.dpi.inpe.br/prodes digital/prodesmunicipal.php $>$

KAIMOWITZ, D.; ANGELSEN, A. Economic models of tropical deforestation: a review. CIFOR Center for International Forestry Research, Bogor, Indonesia, 1998. 


\section{MARGULIS, S. Causas do}

desmatamento da Amazônia brasileira. Brasília: Banco Mundial, 2003.

MARGULIS, S. Quem são os agentes do desmatamento na Amazônia e por que eles desmatam? Brasília: Banco Mundial, 2001.

\section{NEPSTAD, D. C. Forest regrowth} in abandoned pastures of eastern Amazonia: limitations to tree seedling survival and growth, New Haven, 1989. Tese (Doutorado) - Yale University, 1989. $234 \mathrm{p}$

NEPSTAD, D.; CARVALHO, G.; BARROS, A. C.; ALENCAR, A.; CAPOBIANCO, J. P.; BISHOP, J.; MOUTINHO, P.; LEFEBVRE, P.; SILVA Jr, U. L. Road paving, fire regime feedbacks and the future of

Amazon forests. Forest Ecology and Management, p. 1-13, 2001.

NEPSTAD, D.; STICKLER, C.; ALMEIDA, O. A globalização das induistrias de soja e gado na Amazônia: oportunidade para conservação. Disponível em: $<$ http://www.amazonia.org.br/ arquivos $/>$. Acesso em: fev. 2008.

PFAFF, A. S. What drives deforestation in the Brazilian Amazon. Evidence from satellite and socioeconomic data. . World Bank, Washington, DC. 1997. (Policy Research Working Paper, n. 1772).
PIKETTY, M. G.; VEIGA, J. B. D.; TOURRAND, J.; ALVES, A. M.; CHAPUIS, R. P.; THALES, M. C.; HOSTIOU, N. C. N.; VENTURIERI, A. Por que a pecuária está avançando na Amazônia Oriental? In : DORIS, Sayago; JEAN-FRANÇOIS, Tourrand; MARCEL; Bursztyn (eds.). Amazônia: cenas e cenarios. Brasília: Universidade de Brasilia, p. 169-192. 2003.

\section{REIS, E.; MARGULLIS, S.}

Options for slowing

Amazon jungle clearing. In: R. DORNBUSCH, R.; POTERBA, J. Economic policy responses to global warming. (Ed.) Cambridge, MA, MIT Press, 1991

REIS, E.; GUZMAN, R. An econometric model of Amazon deforestation. In: BROWN, K.; PEARCE, D. (Eds.). The causes of tropical deforestation, the economic and statistical analysis of factors giving rise to the loss of tropical forests.

University College London Press, London, p. 172-191, 1994.

REIS, E.; MARGULIS, S. Perspectivas econômicas do desflorestamento da Amazônia. IPEA, 1991. (Texto para Discussão, 215).

REIS, E. Os impactos do pólo siderúrgico de Carajás no desflorestamento da Amazônia brasileira. A economia brasileira em perspectiva, Rio de Janeiro, IPEA, v. 2, p. 691-715, 1996.
RIBEIRO, C.; ALMEIDA, O.; AMARAL RIBEIRO, S.; TONELLO, K.; LIMA, K Expansão da pecuária de bovinos e desafios de sustentabilidade da atividade na Amazônia Legal. III Workshop Brasil - Japão em Energia, Meio Ambiente e Desenvolvimento Sustentável, 2006.

RODRIGUES, R. L. V. Analise dos fatores determinantes do desflorestamento na Amazônia Legal. 2004. Tese (Doutorado) COPPE - Coordenação dos Programas de Pós-Graduação em Engenharia da UFRJ, Rio de Janeiro, 2004.

SOARES-FILHO, B.; ALENCAR, A.; NEPSTAD, D.; CERQUEIRA, G.; VERA-DIAZ, M. D. C.; RIVERO, S.; SOLORZANO, L.; VOLL, E. Simulating the response of land-cover changes to road paving and governance along a major Amazon highway: the Santaream-Cuiaba; corridor, Global Change Biology, v. 10, n. 5, p. $745-764,2004$

TORRES, M. (Org). Amazônia revelada: os descaminhos ao longo da BR-163. Brasília: CNPq, 2005.

VERÍSSIMO, Adalberto; BARRETO, Paulo; MATTOS, Marli; TARIFA, Ricardo; UHL, Christopher. In. ALMEIDA,

Oriana. (Org). Impactos da atividade madeireira e perspectivas para o manejo sustentável da floresta numa velba fronteira da Amazônia: o caso Paragominas. Belém: Imazon, 1996. p. 9-37.
WEINHOLD, D.; REIS, E. J. Model evaluation and causality testing in short panels: the case of infrastructure provision and population growth in the Brazilian Amazon, Journal Of Regional Science, v. 41, n. 4, p. 639-658., 2001

YOUNG, C. Public policies and deforestation in the Brazilian Amazon. Planejamento e Politicas Públicas, IPEA, n. 18, 1998.

$\ldots$

Este artigo contou com o

- financiamento do CNPq nos - projetos MCT/CNPq/PPG7 : - 048/2005 e edital CNPq " "casadinho"-Edital : CNPq 07/2006 - (processo 620235/2006-3). - Os autores agradecem os

- frutiferos debates do

- Professor José Nilo Jr.

- e Professor Paul Cooney do : PPGECONOMLA/UFPA.

E-mail de contato dos autores:

' rivero@ufpa.br

orian@@

avila.saulo@gmail.con

'wesleypo@ufpa.br

Artigo recebido em dezembro de 2008;

aprovado em maio de 2009. 